\title{
なだれどめ階段工計算式の一試案
}

\section{四手井綱 英}

1. 階段工は川尼に於て高橋喜平が試み，秋田営林局管內で石川静一が行つて以来各所で実行せら れ，その效果は一般に認められるに到つたが，其の施行に際しての基本的な階段巾，階段間隔の計算 式は確立されていないので, 経験上から只適当と思われる工事を行うている現状である。従つて其の 工事の効果に関しての不安が多い。

筆者は高橋等と共に十百町で斜面の積雪の征行及階段工の效果試験を行つて見た結果, 此の計算式 の必要を痛感したので, 種ふ検討した結果一応考え方がまとまつたので, 報告するととにした。勿論 この計算式は一試案に留り，自分としても頗る不満足なものであるが，一手掛りと考えて諸賢の批判 を得て更に検討したいと思ら。

2. 從来階段工計算式として出ている唯一のものにフランス「サボア」地方で採用されているとい 5下式がある。

$$
\begin{array}{ll}
\mathrm{d}=\mathrm{K} 1 \cot (\alpha-\beta) & \\
\mathrm{d}=\text { 上下階段の軸間距離, } & \quad \mathrm{l}=\text { 階段工の巾員 } \\
\alpha=\text { 山腹傾斜角 }, & \beta=\text { 雪崩発生最小傾斜角 }\left(24^{\circ}\right) \\
\mathrm{K}=\frac{\mathrm{D} / 1}{\cot \alpha}, & \mathrm{D}=\text { 連続階段之せる場合の軸間距離 }
\end{array}
$$

一雪水, 3 石川静一の報文より—

叉，高橋は経験上次の式を求めている。

$$
1=\frac{1}{7} \mathrm{~h}
$$

$l=$ 階段工の川員,$h=$ 上下階段の重直高

本式は又次の如く書換えられる。

$$
\begin{array}{r}
d / 1=7 \cot \alpha \\
d=71 \cot \alpha \\
\alpha=\text { 山腹傾斜角 }
\end{array}
$$

第 1 図階段工の断面図

両式共に傾斜角のみを因子としたもので, 積 雪量, 質或は地面之覍雪之の摩擦俰数等の因子. を考えていない。

3. 階段工去る「そてなだれ防止原因を 考察する之，次の様な諸因が考えられる。

第 1図に階段工上の積雪の断面を模式的に示 したが，傾斜面上の積雪は積雪初期より徐ふに 滑降して行を，階段工が「なだれどめ」として 充分な巾を持つている時は滑降した積雪膡は 段上飞 $1 \sim 2$ 回程折りた小まれて, 其の後は殆 んぞ安定した状態を呈して春迄持ちてたえる場

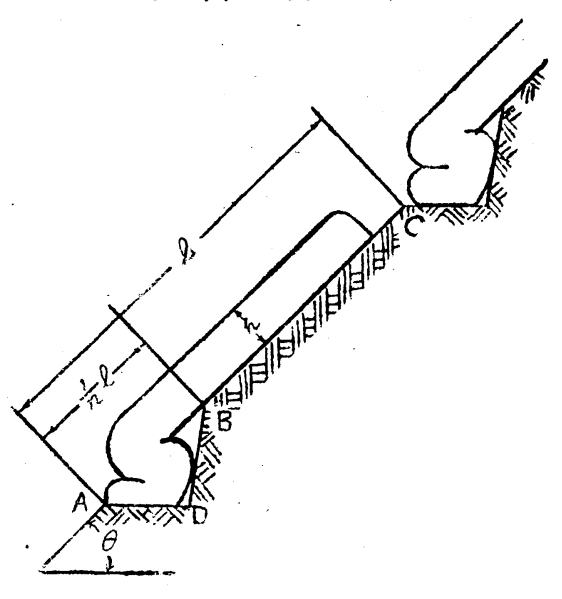
合が普通に見られる状況である。 
階段巾が狭いと，滑降した雪は段面を乗り越えて滑落するか，段面の積雪と共にすうつてしまう。

階段面で $1 \sim 2$ 日程折りたたまれた後, 安定した状態を考え, 此の場合斜面の積雪の滑落を支えて 之の力とつり合つている力は大をく区分して次の 2 が考えられる。

i) 階段面の $\mathrm{AB}$ 線沿亏積雪の総抗剪力。

ii) 階段面の AD 飞於ける積雪の地面に対する摩擦抵抗。

(註) 上の階段面と傾斜面との間の積雪に作用する抗張力は小さいので，斜面の積雪の滑行により，極初 期に切れるか，ひびて薄くなるから考虑外とする。

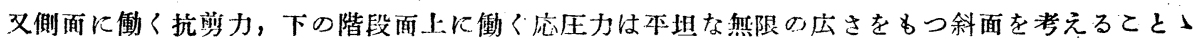
して論外飞置く。其の他可塑体の持つ性啠も無視する。

今上下階段間の斜距離 $\mathrm{AC}$ を $1, \mathrm{AB}$ の階段面斜距離を $\frac{1}{\mathrm{n}} \mathrm{l}$, 平均積雪深（斜面と直角な）を $\mathrm{h}$, 山腹傾斜角を $\theta$, 積雪平均密度を $\boldsymbol{P}$, 地面之䅡雪之の摩擦係数を $\mu, \mathrm{AB}$ 面に於ける平均抗剪力 $\sigma \mathrm{s}$ $(\mathrm{g} / \mathrm{cm})$ とし, 前記の様に斜面の雪は滑行して, 階段面で, 長さ $\mathrm{AB}=\frac{1}{\mathrm{n}} 1$ の 2 倍丈折りた〉まれ て後安定した状態を考えると, 斜面 $\mathrm{BC}$ 上に残る積雪の単位巾員に対する重量 (W) は次の如くを る。

$$
\mathrm{W}=\frac{\mathrm{n}-2}{\mathrm{n}} \rho \mathrm{lh}
$$

この皘雪重量は斜面上に働く摩擦で一部支えられるから傾斜方向への滑行力即ち下向に傾斜に沿つ て生叔力 $\left(\mathrm{C}^{\prime}\right)$ は

$$
\mathrm{C}_{;}=\frac{\mathrm{n}-2}{\mathrm{n}} \rho \ln (\sin \theta-\mu \cos \theta)
$$

となる。之の $\mathrm{C}_{\mathrm{p}}$ を前記の $\mathrm{AB}$ 面に於ける積雪の抗愬力或は $\mathrm{AD}$ 面に於ける摩擦抵抗が支持してい るわけである。

故に上記の様に階段上の支持力を 2 亿区分して考えると，

i) AD 面の摩擦抵抗が A B 面の抗剪力上り著しく大学名場合。

此の場合は A B 面での総抗剪力 ( $2 \sigma s)$ が $C_{p}$ より大きいか等しい場合は斜面の積雪は安定する ととになる。即ち

$$
\begin{aligned}
& \Sigma \sigma \mathrm{s}=\frac{1}{\mathrm{n}} \mathrm{l} \sigma \mathrm{s} \\
& \frac{1}{\mathrm{n}} \mathrm{l} \sigma \mathrm{s} \geqq \frac{\mathrm{n}-2}{\mathrm{n}} \rho \mathrm{lh}(\sin \theta-\mu \cos \theta) \\
& \therefore \mathrm{n} \leqq 2+-\rho \frac{\sigma \mathrm{s}}{\rho(\sin \theta-\mu, \cos \theta)}
\end{aligned}
$$

(2)式が成立つ時には「なだれ」が防止出来ることになる。

ii） A B 面の抗剪力が $\mathrm{AD}$ 面の摩擦抵抗より著しく大なる場合。

此の場合は AD 面の摩擦抵抗が $C_{t}$ ，を支えることになる。

C：の力を階段面 A D r直角な方向之平行な方向の二分力に区分すると，前者は段面の摩擦力 (R)になり，後者は滑行力 (S) になる。即ち

$$
\begin{aligned}
& \mathrm{S}=\mathrm{C}_{\mathrm{p}} \cos \theta=\frac{\mathrm{n}-2}{\mathrm{a}} \rho \mathrm{lh}(\sin \theta-\mu \cos \theta) \cos \theta \\
& \mathrm{R}=\mathrm{C}_{\mathrm{p}} \sin \theta=\frac{\mathrm{n}-2}{\mathrm{n}} \rho \mathrm{lh}(\sin \theta-\mu \cos \theta) \sin \theta
\end{aligned}
$$

階段面に作用する摩擦力には此の外，階段面上の積雪の重量 $\frac{2}{\mathrm{n}} \rho \mathrm{lb}$ がある。(前記の様に階段面 上には $\frac{1}{\mathbf{n}} 1$ の長さの積雪が 2 回折りたなまれたとしての計算である。) 
故に此の場合の段面に作用する総摩擦扯抗 (F) は

$$
\mathbf{F}=\mu\left\{\frac{\mathrm{n}-2}{\mathrm{n}} \rho \mathrm{lh}(\sin \theta-\mu \cos \theta) \sin \theta+\frac{2}{\mathrm{n}} \rho \mathrm{lh}\right\}
$$

となる。

其所で(3)式の $\mathbf{S}$ が(5)式の Fより小さいか等しい場合は斜面の雪は安定する事になるから次の関係式 が求められる。

即ち

$$
\left.\frac{\mathrm{n}-2}{\mathrm{n}} \rho \mathrm{lh}(\sin \theta-\mu \cos \theta) \cos \theta \leqq \mu\left\{\frac{\mathrm{n}-2}{\mathrm{n}} \rho \mathrm{lh}(\sin \theta-\mu \cos \theta) \sin \theta\right)+\frac{2}{\mathrm{n}} \rho \mathrm{lh}\right\} .
$$

$$
\mathbf{n} \leqq 2+\frac{2 \mu}{\sin \theta} \frac{2 \mu}{\cos \theta\left(1+\mu^{2}\right)-\mu}
$$

(6)式が成立する時に「なだれ」がとまるととになる。

(2)及(6)式を併せ考えると次の関係式が求められる。

$$
2+\frac{\sigma \mathrm{s}}{\rho \mathrm{h}(\sin \theta-\mu \cos \theta)} \geqq \mathbf{n} \leq 2+\frac{2 \mu}{\sin \theta \cos \theta\left(1+\mu^{2}\right)-\mu}
$$

(7)式よりてれを求めると，A

B と A C との比が求められ

ることになる。

以上の諸式は，櫴雪が第 1 図の様な状態になつた時に㴊 体化したものとして考察した のであるが，積雪は㴊体でな く，所謂可塑体としての性質 が強く, 斜面の雪は哉行し, 沈降し，だれ，才れ等の現象 を呈するのであるから，此の 様な単純な考え方では不立分 なととは分つているが，雪の 時間的変化は樍雪当初は急激 であるが, 其の後は頗る緩漫 で，或る期間をとれば俩体と みなして，大して不都合のな 禓合も多く，又時間を考え る事はこの様な実用を目的と した場合には繁雑になるばか りであるので，現段階では以 上の考え方で满足したいと思 5。

(2)式には $\sigma \mathrm{s}, \rho, \mathrm{h}, \theta, \mu$ の 5 種の因子があるから，此 の内 $\sigma \mathrm{s}, \rho, \theta$ 几適当な常数 を与え, $\theta$ 及び $\mu$ の変化に対 するnの変化を計算して見よ

第 1 衰 $\mathrm{n}=2+\frac{\sigma \mathrm{S}}{\rho \mathrm{h}(\sin \theta-\cos \theta)}$ より算出した $\mathrm{n}$ の值

\begin{tabular}{r|r|r|r|r|r|r|r|r|r|r}
\hline $\boldsymbol{\theta}$ & 0.1 & 0.2 & 0.3 & 0.4 & 0.5 & 0.6 & 0.7 & 0.8 & 0.9 & 1.0 \\
\hline 20 & 7.7 & 11.5 & 25.8 & - & - & - & - & - & - & - \\
25 & 6.3 & 8.0 & 11.5 & 25.8 & - & - & - & - & - & - \\
30 & 5.4 & 6.3 & 8.0 & 11.5 & 25.8 & - & - & - & - & - \\
35 & 4.8 & 5.5 & 6.5 & 8.0 & 10.9 & 19.9 & - & - & - & - \\
40 & 4.6 & 4.9 & 5.5 & 6.3 & 7.7 & 10.0 & 14.9 & - & - & - \\
45 & 4.2 & 4.5 & 4.9 & 5.4 & 6.1 & 7.1 & 8.8 & 12.2 & 22.4 & - \\
\hline 50 & 4.0 & 4.3 & 4.5 & 4.8 & 5.2 & 5.7 & 6.5 & 7.5 & 9.5 & 13.0 \\
55 & 3.9 & 4.0 & 4.2 & 4.4 & 4.7 & 5.1 & 5.5 & 6.0 & 6.6 & 7.7 \\
60 & 3.7 & 3.9 & 4.0 & 4.1 & 4.2 & 4.5 & 4.8 & 5.0 & 5.4 & 5.9 \\
65 & 3.6 & 3.7 & 3.8 & 3.9 & 4.0 & 4.2 & 4.4 & 4.5 & 4.7 & 4.9 \\
70 & 3.6 & 3.6 & 3.7 & 3.8 & 3.9 & 4.0 & 4.1 & 4.2 & 4.3 & 4.4 \\
\hline
\end{tabular}

第 2 表 $\mathrm{n}=2+\frac{2 \mu}{\sin \theta \cos \theta\left(\overline{1+\mu^{2}}\right)-\mu}$ より算山した $\mathrm{n}$ の值

\begin{tabular}{r|r|r|r|r|r|r|r|r|r|r}
\hline $\boldsymbol{\theta}$ & 0.1 & 0.2 & 0.3 & 0.4 & 0.5 & 0.6 & 0.7 & 0.8 & 0.9 & 1.0 \\
\hline 20 & 2.9 & 5.0 & 13.3 & - & - & - & - & - & - & - \\
25 & 2.7 & 4.0 & 6.2 & 20.6 & - & - & - & - & - & - \\
30 & 2.6 & 3.6 & 5.3 & 9.2 & 22.0 & - & - & - & - & - \\
35 & 2.5 & 3.4 & 4.8 & 7.5 & 12.4 & 32.6 & - & - & - & - \\
40 & 2.5 & 3.3 & 4.6 & 6.8 & 10.9 & 20.1 & 48.5 & - & - & - \\
45 & 2.5 & 3.2 & 4.4 & 6.4 & 10.0 & 17.0 & 33.1 & 82.0 & - & - \\
\hline 50 & 2.5 & 3.3 & 4.6 & 6.8 & 10.9 & 20.1 & 48.5 & - & - & - \\
55 & 2.5 & 3.4 & 4.8 & 7.5 & 12.4 & 32.6 & - & - & - & - \\
60 & 2.6 & 3.6 & 5.3 & 9.2 & 22.0 & - & - & - & - & - \\
65 & 2.7 & 4.0 & 6.2 & 20.6 & - & - & - & - & - & - \\
70 & 2.9 & 5.0 & 13.3 & - & - & - & - & - & - & - \\
\hline
\end{tabular}


5 。

十日町の過去の測定による 之，稍雪中期治於ける程雪平 出于抗剪力は $100 \sim 150 \mathrm{~g} / \mathrm{cm}^{2}$ であり, 踤度平均は! 35 , 皘 雪深は 2〜2.5m 位であるか 5 , 此所で, $\sigma_{S}=100 \mathrm{~g} / \mathrm{cm}^{2} \rho$ $=0.35, \mathrm{~h}=2.5 \mathrm{~m}$ とすると $\theta$ 之, $\mu$ の変化泟対する $\mathrm{n}$ の変 化は第 1 表の如くなる。

(6)式は $\theta$ と $\mu$ との 2 因子 であるから，同様にこの両因 子の変化に対する $\mathrm{n}$ の值を求 めると第 2 表の様になる。

この両表より(7)式により， 同一の $\theta$ 及び $\mu$ に対する の值は小さな方をとつて，両 表を一つに取括めたのが第3 表及第 2 図である。

本図表により，施行地の傾 斜角 $\theta$ 己摩擦係数 $\mu$ を決定す ると，其の個所の $\mathrm{n}$ 即ち階段 巾之階段距離の比が分り，階 段巾を決定すればビれ丈の間 隔を置いて，段切を行えば良 レが゙求められる。

$\mu の$ 值は测定困難ななめ実 测例が少いが，一般に「なた
禹 3 表 第 $1 ， 2$ 表から小さな值を取つて求めた $\mathrm{n}$ の值

\begin{tabular}{r|r|r|r|r|r|r|r|r|r|r}
\hline $\boldsymbol{\theta}$ & \multicolumn{1}{|c|}{0.1} & 0.2 & 0.3 & 0.4 & 0.5 & 0.6 & 0.7 & 0.8 & 0.9 & 1.0 \\
\hline 20 & 2.9 & 5.0 & 13.3 & - & - & - & - & - & - & - \\
25 & 2.7 & 4.0 & 6.2 & 29.6 & - & - & - & - & - & - \\
30 & 2.6 & 3.6 & 5.3 & 9.2 & 22.0 & - & - & - & - & - \\
35 & 2.5 & 3.4 & 4.8 & 7.5 & 10.9 & 19.9 & - & - & - & - \\
40 & 2.5 & 3.3 & 4.6 & 6.3 & 7.7 & 10.0 & 14.9 & - & - & - \\
45 & 2.5 & 3.2 & 4.4 & 5.4 & 6.1 & 7.1 & 8.8 & 12.2 & 22.4 & - \\
\hline 50 & 2.5 & 3.3 & 4.5 & 4.8 & 5.2 & 5.7 & 6.5 & 7.5 & 9.5 & 13.0 \\
55 & 2.5 & 3.4 & 4.2 & 4.4 & 4.7 & 5.1 & 5.5 & 6.0 & 6.6 & 7.7 \\
60 & 2.6 & 3.6 & 4.0 & 4.1 & 4.2 & 4.5 & 4.8 & 5.0 & 5.4 & 5.9 \\
65 & 2.7 & 3.7 & 3.8 & 3.9 & 4.0 & 4.2 & 4.4 & 4.5 & 4.7 & 4.9 \\
70 & 2.9 & 3.6 & 3.7 & 3.8 & 3.9 & 4.0 & 4.1 & 4.2 & 4.3 & 4.4 \\
\hline
\end{tabular}

第 2 図 $\theta, \mu$ と との関保

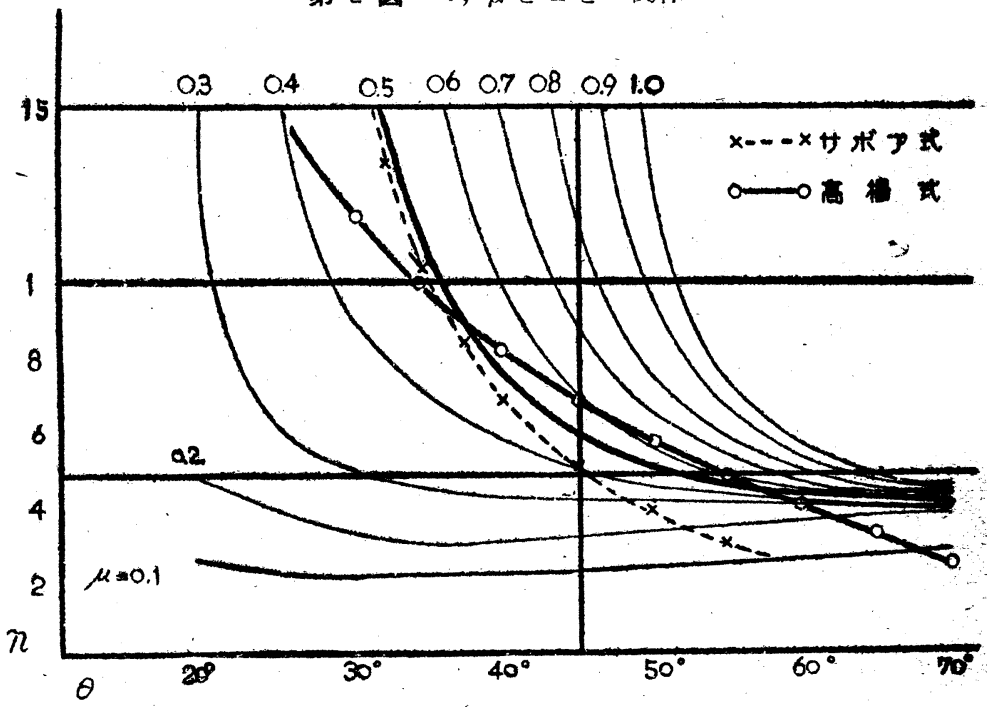

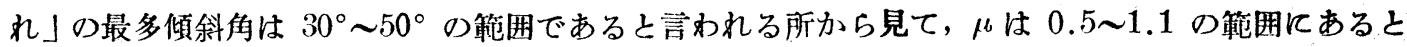
考えられ，安全性を考虑して $\mu=0.5$ をとれば良いであろう。

第 2 図には「サボア」式 (A) と高橋式 (B) の值を㨂大して置いたが両者共 $\mu=0.5$ に近い場合 を示している。

4. 以上階段工の算定式の一試案を記したのであるが，是は今後更に現地の結果及模型実験等を行 つて，実際例との適合具合につき検討して行きたんと思つている。（昭 $25 . N .4$ 釜淵にて） 